\title{
Changes in Plasma Steroid Hormone Levels and Gonad Development by the Control of Photoperiods and Water Temperatures on Timing of Sexual Maturity of Rockfish (Sebastes schlegeli)
}

\author{
Hea-Ja Baek ${ }^{1 *}$, Moo-Eog Park ${ }^{2}$, Young-Don Lee ${ }^{3}$, Hyung-Bae Kim ${ }^{4}$ \\ and Sum Rho \\ ${ }^{1}$ Department of Marine Biology, Pukyong National University, Busan 608-737, Korea \\ ${ }^{2}$ Fisheries Resources Development Institute, Youngduk-gun, Kyoungbuk 766-852, Korea \\ ${ }^{3}$ Marine and Environmental Research Institute, Cheju National University, Jeju 695-814, Korea \\ ${ }^{4}$ Department of Marine Biotechnology, Kangwon Provincial University, Kangnung 210-814, Korea
}

\begin{abstract}
Plasma steroid hormone levels in the viviparous rockfish (Sebastes schlegeli) were examined in relation to gonadal histology under controlled photoperiods and water temperatures. To investigate those effects in $S$. schlegeli the photoperiod was maintained at 15L:9D in June and then it was gradually decreased to $9 \mathrm{~L}: 15 \mathrm{D}$ in October. It was then gradually increased to $12 \mathrm{~L}: 12 \mathrm{D}$ in January, followed by $14 \mathrm{~L}: 10 \mathrm{D}$ in February. The water temperature was $19-20^{\circ} \mathrm{C}$ in July. From August to October, it was from $18^{\circ} \mathrm{C}$ to $12^{\circ} \mathrm{C}$. Then, it was dropped to a low of $9-11^{\circ} \mathrm{C}$ in November to December and then gradually increased to $14-15^{\circ} \mathrm{C}$ in February. In females, both plasma estradiol-173 (E2) and testosterone (T) levels from August to February showed a similar pattern in both the treatment and the control groups. In the treatment group, the peaks of plasma E2 and T were observed in November, and the peaks were closely correlated to histological observations. Oocytes contained many yolk globules (final vitellogenic oocytes), and oocytes at the migratory nucleus stage increased in size. Plasma levels of progesterone did not change much throughout the experimental period. However, in the control group, the peaks of E2, T, and progesterone were observed in February. These results indicate that the controlled photoperiod and water temperature accelerated sexual maturity, corresponding to the advancement of plasma E2 and T peaks by approximately 3 months. In males, plasma $\mathrm{T}$ levels showed a similar pattern from August to October in the treatment and control groups, though levels in the treatment group were higher than those in the control group. From histological observations, the treatment group copulated one month earlier.
\end{abstract}

Key words: Rockfish, Photoperiod, Temperature, Steroid hormone, Maturation

\section{Introduction}

In aquacultural industry, the control of reproductive process of fish by the manipulation of environmental factors is one of the most important application in commercial broodstock management. Photoperiod and/or water temperature are generally recognized as the principal environmental factors in controlling gonad development (Lam, 1983). The effect of photoperiod and/or temperature on gonad development is mediated through the endocrine system that controls reproduction. This is achieved by corresponding

\footnotetext{
*Corresponding author: hjbaek@pknu.ac.kr
}

alteration in the activity of the gonadotropin releasing hormone (GnRH)-gonadotropic hormone (GtH)gonadal axis. The changes in GnRH and GtH lead to the seasonal changes in the gonadal steroids: estradiol-173 estrone, testosterone, 17a, 20ß-dihydroxy-4-pregnen-3-one and vitellogenin following photoperiod and temperature manipulation (Carrillo et al., 1993; Zanuy et al., 1995; Bromage et al., 2001).

Many studies on reproductive endocrine function of gonadal steroids has been conducted for the oviparous fishes. There is limited information on endocrine function of steroids in viviparous fishes, which possess many different reproductive patterns 
(Wourms et al., 1988).

The viviparous rockfish (Sebastes schlegeli) is an important narine species for commercial fish culture in Korea. Research programs have been performed in the development of embryo and larvae (Yamada and Kusakari, 1991; Kusakari, 1991), sex differentiation (Lee at al., 1996), early life history (Kim and Han, 1991), growth and maturation (Hyun and Rho, 1996; Chung and Chang, 1995), and reproductive cycles (Nc.gahama et al., 1991; Baek et al., 2000).

Park et cl., (2001) demonstrated that the copulation and partur tion of S. schlegeli could be advance 2-3 months by controlling photoperiod and temperature. But they did not present hormonal changes of the fish for the advanced maturation. This study measured plasma steroid changes together with gonadal histology, under the controlled photoperiod and temperature regimes on timing maturation. Plasma estradiol173 , testosterone and progesterone levels were monitored in females, and plasma testosterone levels were monitored in males.

\section{Materials and Methods}

\section{Fish}

On May 1 1996, 272 adults fish of rockfish (female, $40-48 \mathrm{~cm}$ i length and $1,000-1,500 \mathrm{~g}$ in weight; male, $29-34 \mathrm{~cm}$ in length and $400-670 \mathrm{~g}$ in weight) were divided in o four groups, two for the treatment and two for the control. Each group was reared in a 5 ton recirculating tank system which was facilitated at Marine Research Institute, Cheju National University.

\section{Photoperiod and water temperature regulation}

For this research, we set up an artificial cultured condition or the $S$. schlegeli, time table for photoperiod anc water temperature was based on reproductive cycle of $S$. schlegeli around the southern coast of Korea. From June, daylength was maintained 15 hr light per day (15L/9D) and then it was gradually decreased to $9 \mathrm{hr}$ per day (9L/15D) in October. From January tc February, it was maintained from $12 \mathrm{~L}$ to $14 \mathrm{~L}$. Water temperature was $19-20^{\circ} \mathrm{C}$ in July. From August to October, it was from $18^{\circ} \mathrm{C}$ to $12^{\circ} \mathrm{C}$. Then from November to December, it was dropped to the lowest, $9-11^{\circ} \mathrm{C}$ and then gradually increased to $14-1$ $5^{\circ} \mathrm{C}$ in February. The light intensity at the water surface was 250 lux. The control groups were exposed to light and tzmperature of natural condition as in Park et al. (2001).
Fish were fed at $1-1.5 \%$ body weight/day and checked for maturity at monthly or bimonthly from June 1996 to February 1997. In each experiment, the fish were anaesthetized in a solution of 2phenoxy-ethanol $(0.3 \mathrm{~mL} / \mathrm{L})$, checked for signs of sexual maturation. Gonads and blood samples were taken from 10 individuals (5 females and 5 males) in each group. The blood samples were immediately centrifuged, and the plasma was stored at $-20^{\circ} \mathrm{C}$ until analysis for testosterone in both sexes, and estradiol173 and progesterone for females. Gonads were fixed in Bouin's solution for histological processing.

\section{Steroid analysis}

Plasma levels of the sex steroids testosterone, estradiol-17 $\beta$ and progesterone were determined by radioimmunoassy (Aida et al. 1984). Antiserum against testosterone and progesterone were purchased from Sigma Chemical Co. and estradiol-1 73 was purchased from ICN ImmunoBiologicals, and tritium labeled steroids were purchased from Amersham International. Intra-assay variations were $5.8 \%$ for E2, $3.4 \%$ for $\mathrm{T}$ and $9.8 \%$ for progesterone. Inter-assay variations were $12.7 \%, 11.5 \%$ and $14.2 \%$, respectively. The lower limit of detection of steroids were $7.5 \mathrm{pg} / \mathrm{mL}$. All procedures were carried out in National Fisheries Research and Development Institute.

\section{Histological procedures}

The gonads were fixed in Bouin's solution. Serial sections of 5-6um were prepared by the usual paraffin method and stained with Hansen's haematoxylineosin. Microscopical analysis of the gonads were carried out according to Bae et al. (1998).

\section{Results}

\section{Females}

At the start of experiment, the ovaries contained oocytes $(<50 \mu \mathrm{m}$ in diameter) in perinucleolar stage that were uniformly and strongly basophilic. In August, the treatment group contained oocytes at stages of early development (perinucleolar and oil droplets). The size of the oocytes in oil droplet stage ranges from 100 to $140 \mu \mathrm{m}$ in diameter (Fig. 1A). In the control group, the most oocytes were at the

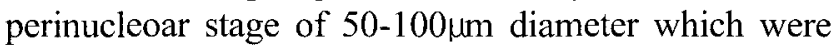
strongly basophilic. In October, small vacuoles corresponding to the yolk vesicles present in cytoplasm and yolk granules began to accumulate in oocytes between 230 and $280 \mu \mathrm{m}$ in the treatment group (Figs. $1 \mathrm{~B}, 1 \mathrm{C})$. In the oocyte of the most advanced stage 

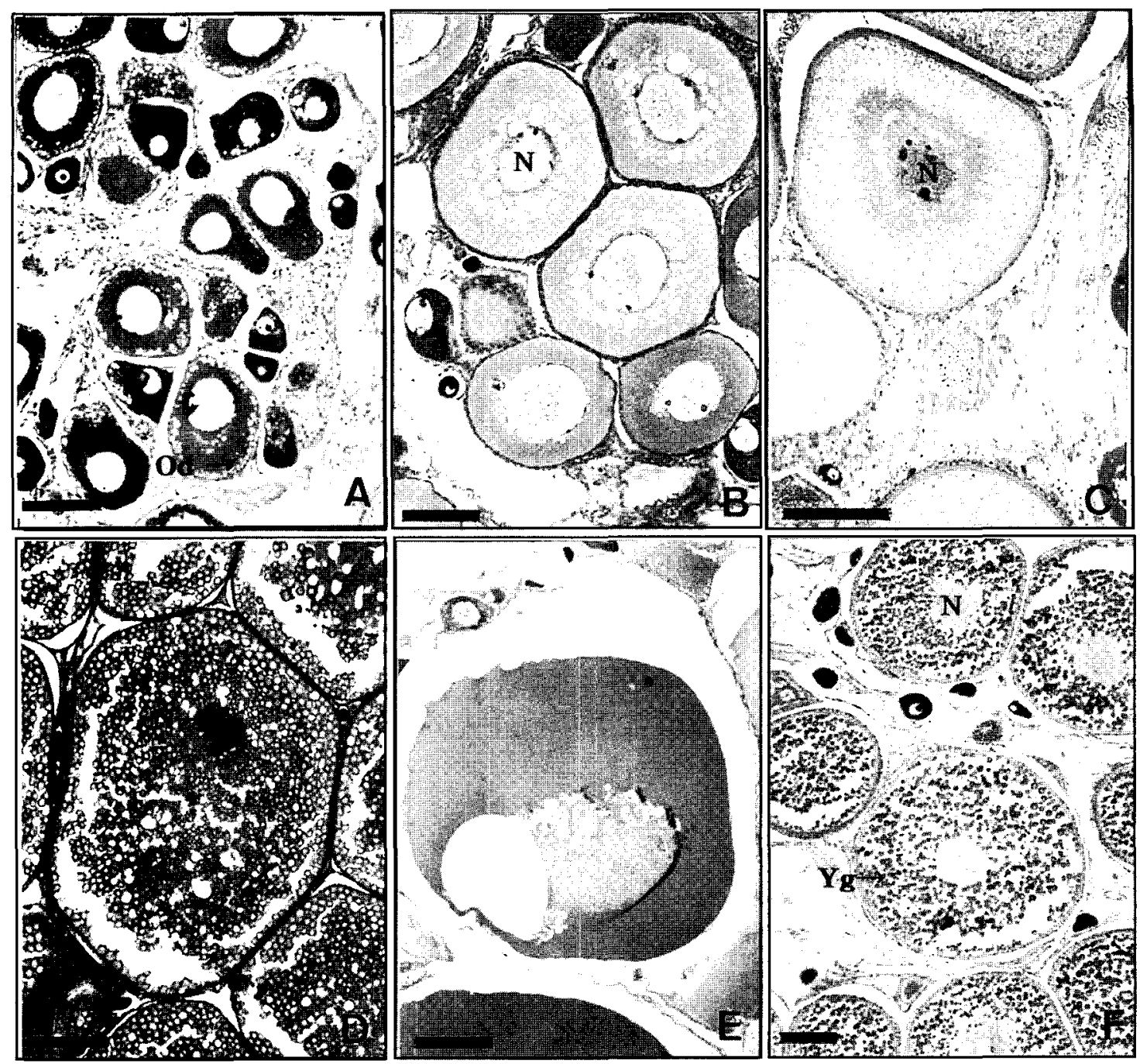

Fig. 1. Section of the ovary in Sebastes schlegeli during August to February. A: Perinucleolar and oil droplet stage in August (treatment group), B-C: Yolk vesicles and small yolk granules in the inner part of the cytoplasm in October (treatment group), D: Oocytes of migratory nucleus stage in November (treatment group), E: Fertilized eggs distributed within ovarian cavity in February (treatment group), F: Oocytes with many yolk globules in January (control group). Scale bar $=100 \mu \mathrm{m}$.

observed in this group, the nucleus was seen moving towards the animal pole (migratory nucleus stage). At this stage the oocyte diameter was 480 to $600 \mu \mathrm{m}$ with many yolk globules occupying the entire cytoplasm in November (Fig. 1D). In January and February, internally fertilized eggs were observed in treatment (Fig. 1E). The control fish oocytes contained many yolk globules from November to January (Fig. $1 \mathrm{~F})$ and then migratory nucleus stage oocytes were observed in February.

Plasma levels of estradiol-1 7 , testosterone and progesterone in female are shown in Fig. 3. From June to October, estradiol-173 and testosterone levels in control and treatment groups remained within the range of $0.86 \pm 0.02-1.51 \pm 0.38$ and $0.13 \pm 0.0 \digamma-0.24 \pm$ $0.01 \mathrm{ng} / \mathrm{mL}$, respectively. In November, the highest estradiol-173 and testosterone levels were, in the treatment group, $5.01 \pm 2.45$ and $6.33 \pm 1.32 \mathrm{ng} / \mathrm{mL}$, respectively, and after November those levels were decreased, while in the control group they peaked in February as $6.54 \pm 0.77$ and $3.28 \pm 0.19 \mathrm{ng} / \mathrm{mL}$, respectively. However, plasma level of progesterone did not show much difference between the control and the treatment groups by November, but, in the control group, the highest level $(8.40 \pm 0.93 \mathrm{ng} / \mathrm{mL})$ was detected in February. 

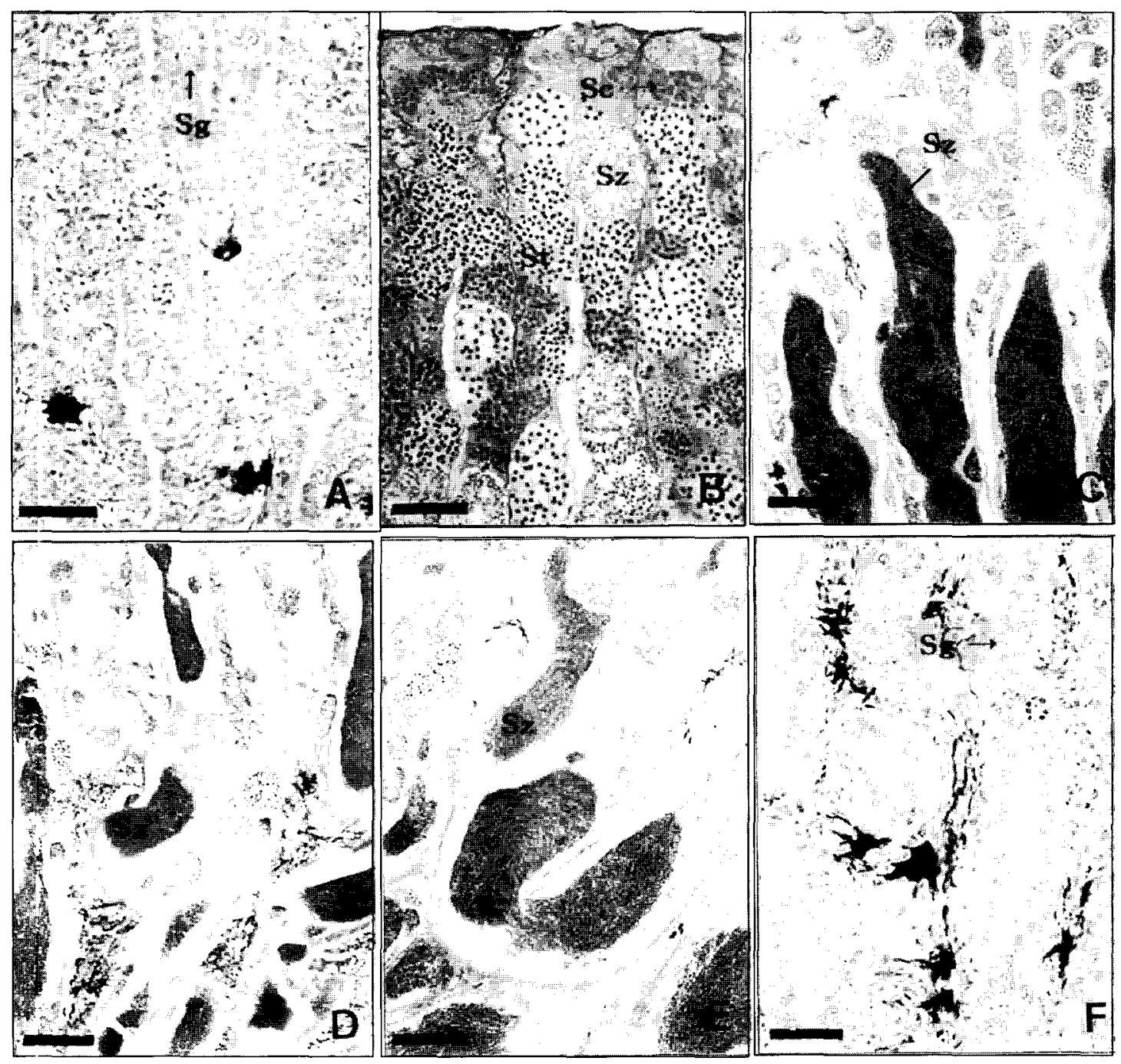

Fig. 2. Section of the testis in Sebastes schlegeli during June to February. A: Spermatogonia proliferation stage in June (control group), B: Numerous spermatocytes, spermatids, and few spermatozoa in August (treatment group), C- J: Ripe and spent stage from October to November (treatment group), E: Ripe and spent stage in late November (control group), F: Resting stage in February (control/treatment groups). Scale bar $=100 \mu \mathrm{m}$.

\section{Males}

For the nales, the experiment started in June, the spermatogonia in the testis were proliferated and increased in number (Fig. 2A). In August, the active spermatogenic testes contained a large number of spermatocytes and spermatids in the treatment fish (Fig. 2B). A small number of spermatozoa had also appeared in the same testes. From October to November the serniniferous tubules were larger in size with an increase in the number of spermatozoa (Fig. 2C). In the late of November, residual spermatozoa were still presert in clusters in the seminiferous tubules (Fig. 2D), while in the control, predominating spermatozoa were observed (Fig. 2E). In February, sper- matogonia were along the wall of the seminiferous tubules (Fig. 2F).

During August to. October, the plasma levels of testosterone remained high as $1.43 \pm 0.23-3.12 \pm 2.97$ $\mathrm{ng} / \mathrm{mL}$ for the treatment group, and $0.57 \pm 0.02$ $1.36 \pm 0.17 \mathrm{ng} / \mathrm{mL}$ for the control, and then decreased remarkably to basal levels $(0.03 \pm 0.01-0.12 \pm 0.04$ ng/ml) (Fig. 4).

\section{Discussion}

Environmental factors, such as photoperiod and temperature, may act as cues for the formation of the sexual cycle in viviparous as well as oviparous 

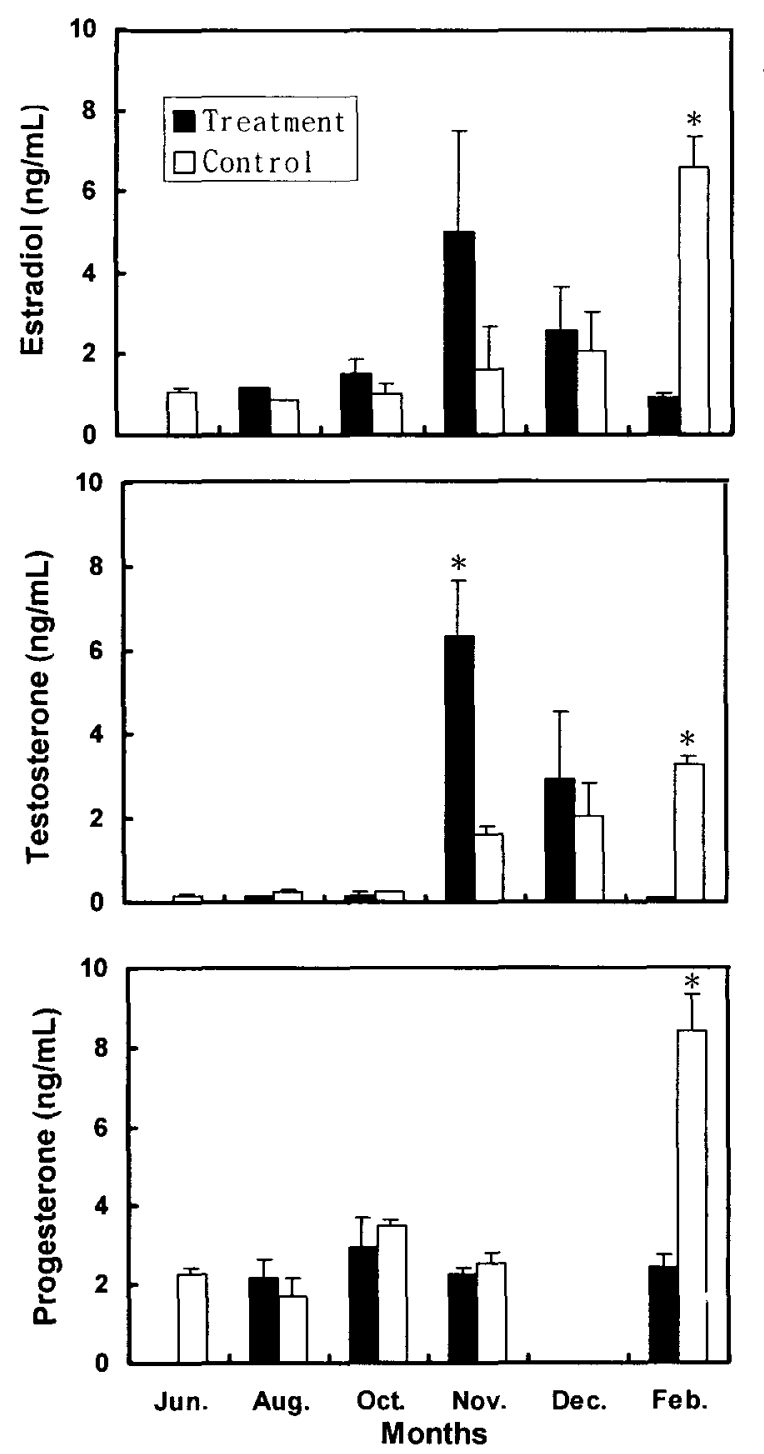

Fig. 3. Changes in plasma estradiol-17 $\beta$, testosterone and progesterone of the treatment and the control groups in female Sebastes schlegeli. Each value represents the mean \pm S.E. Significant differences (*p $<0.05$ ) between treatment and control were determined by Student's t-test.

teleosts. In a viviparous rockfish, genus Sebastes, reproduction is characterized by intralumenal (ovarian lumen) gestation following fertilization of ovulated, mature eggs. (Wourms et al., 1988), that is an evolutionarily advanced mode of reproduction through the relatively primitive forms of matrotrophic viviparity. In the rockfishes, functional maturation of males generally procedes that of females, and mature spermatozoa are delivered by copulation into maturing ovaries and stored there until oocytes have completed their final maturation and ovulation (Takahashi et

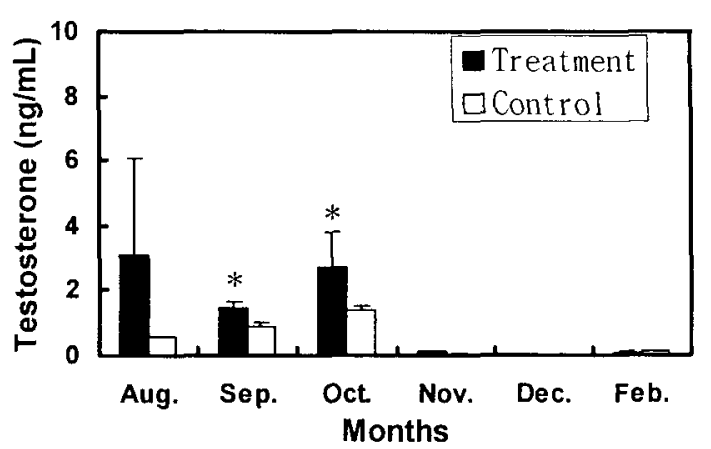

Fig. 4. Changes in plasma testosterone of treatment and control groups in male Sebastes schlegeli. Each value represents the mean \pm S.E. Significant differences $\left({ }^{*} \mathrm{p}<0.05\right)$ between treatment and control were determined by Student's t-test.

al., 1991).

Studies on reproductive biology of Sebaetes has been conducted for many years in Korea and Japan in relation to aquaculture potential. The main target species was S. schlegeli (Kusakari et al., 1977; Kusakari, 1991; Lee and Kim, 1992; Chang et al., 1995; Baek et al., 2000). In Korean south cost, copulation in this species occurs in NovemberDecember, and the sperms are stored until ovulation/ fertilization the following March, and parturition occurs in April-May (Baek et al., 2000; Park et al., 2001). Park et al (2001) reported that the artificial manipulation of photoperiod and water temperature resulted in copulation and parturition advancement by about 2-3 months compared with the control. In the present study, the effect of photoperiod and water temperature on timing of sexual maturity in $S$. schlegeli was monitored through changes in plasma sex steroid levels and gonad histological observation.

The plasma E2 and T levels in females in our study showed a similar pattern during experimental period (August 1996 to February 1997) in the treatment and the control groups. In the treatment group, the plasma E2 and T peaks were observed in November. The peaks were correlated with the result of histological observations, showing oocytes contained many yolk globules (final vitellogenic oocytes) and an increase in the size of oocytes at the migratory nucleus stage in this period. Plasma level of progesterone did not show much difference throughout the experimental period. However, in the control group, the peaks of E2, $\mathrm{T}$ and progesterone ere observed in February. These results indicate that controlled photoperiod and water temperature accelerates 
the sexual maturation by approximately 3 month for female rockfish. This supports the previous work by Park et al. (2001). A similar phenomenon has been described in $S$. inermis, where delayed maturation (1-2 montlss) in ovary was caused by the controlled photoperiod and water temperature (Ko et al., 1998; Chang et al., 2001).

It is interesting to note that plasma E2 and T levels are high during final maturation, which is initiated by migration of the nucleus. Our findings were in accordance with those of some other viviparous fish species (Manire et al., 1995; Kwon et al., 1999), and they proved that high plasma E2 levels has been observed a maturation. Low E2 levels at final maturation is conmon in many fish species as high E2 levels during vitellogenesis. On the other hand, the progesterone levels observed in $S$. schlegeli did not respond to the controlled photoperiod and water temperature conditions. But, in the control group, this steroid peaked at the migratory nucleus stage in February. In S. taczanowskii, serum levels of progesterone were relatively low throughout the annual reproductive cycle (Takemura et al., 1987). Nagahama et al. (19S1) described that, in S. taczanowskii and $S$. schlegt li, among the progestogens, 17k, 20ß-dihydroxy-4-pregnen-3-one plays an important role in final oocyte maturation and the maintenance of gestation, sut progesterone apparently does not play a significe.nt role. From the results of the present study, the possible functions of progesterone in relation to fincl maturation did not appear to be excluded. Low levels of progesterone might reflect changes in product on of other progestogens such as $17 \mathrm{~m}, 20 \beta-$ dihydroxy-4-pregnen-3-one. In our study, $17 \mathrm{z}, 20 \beta$ dihydroxy-4-pregnen-3-one was detectable from only a few individuals.

In the pesent study, the changes in plasma $T$ levels observed in males suggests that testes were apparently not affected by the photoperiod and water temperature conditions. although $\mathrm{T}$ levels in the treatment group were high ar than those in the control group during August to October. However, from the histological observations, the treatment group resulted in one month ear ier copulation. Park et al. (2001) reported also the copulation in $S$. schlegeli could be advanced one month by controlling photoperiod and temperature. Further studies are needed to ascertain the involvement of steroids in the reproductive process other thar testosterone.

\section{Acknowledgements}

This work was supported by the Ministry of Maritime Affairs and Fisheries, Korea.

\section{References}

Aida, K., T. Kato and M. Awaji. 1984. Effects of castration on the smoltification of precocious male masu salmon Oncorhynchus masou. Bull. Jap. Soc. Sci. Fish., 50, 565-571.

Bae, H.C., S.C. Chung, J.J. Lee and Y.D. Lee. 1998. Annual reproductive cycle and embryonic development within the maternal body of the marbled rockfish, Sebastiscus marmoratus from the Cheju Island. J. Kor. Fish. Soc., $31,489-499$.

Baek, J.M., C.H. Han, D.J. Kim, C.W. Park and K. Aida. 2000. Reproductive cycle of a rockfish, Sebastes schlegeli. J. Kor. Fish. Soc., 33, 431-438.

Bromage, N., M. Porter and C. Randall. 2001. The environmental regulation of maturation in farmed finfish with special reference to the role of photoperiod and melatonin. Aquaculture, 197, 63-98.

Carrillo, M., S. Zanuy, F. Prat, R. Serrano and N. Bromage. 1993. Environmental induction of spawning in sea bass. In: Recent Advances in Aquaculture, vol. 4, Roberts, R.J. and J. Muir. eds., Blackwell, Oxford, pp. $43-54$.

Chang, Y.J., H.K. Lim and S.G. Byun. 1995. Gonadal maturation and reproductive cycle in oblong rockfish, Sebastes oblongus. J. Aquacult, 8, 31-46.

Chang, Y.J., H.K. Lim and J.Y. Kwon. 2001. Changes in plasma steroid hormone level in rockfish (Sebastes inermis) by the controlled water temperature and photoperiod. J. Kor. Fish. Soc., 34, 13-16.

Chung, E.Y. and Y.J. Chang. 1995. Ultrastructural changes of germ cell during the gametogenesis in Korean rockfish, Sebastes schlegeli. J. Kor. Fish. Soc., 28, 736-752.

Hyun, C.H. and S. Rho. 1996. Studies on the early growth of rockfish, Sebastes schlegeli. J. Aquacult., 9, 25-42.

Kim, Y.K. and K.H. Han. 1991. The early life history of rockfish, Sebastes schlegeli. Kor. J. Ichthyol., 3, 67-83.

Ko, C.S., Y.J. Chang, H.K. Lim, J.H. Kim and K.C. Cho. 1998. Controlled reproductive cycle of rockfish (Sebastes inermis) by water temperature and photoperiod. J. Kor. Fish. Soc., 31, 713-720.

Kusakari, M. 1991. Mariculture of kurosoi, Sebastes schlegeli. Env. Biol. Fish., 30, 245-251.

Kusakari, M, Y. Mori and K. Kudo. 1977. Studies on the breeding habit of a rockfish, Sebastes schlegeli (Hilgendorf). 2. On the breeding behavior of pregnant fish and the just spawned larvae. J. Hokkaido Fish. Exp. St., 34, 1-11.

Kwon, J.Y., Y.J. Chang Y.C. Shon and K. Aida. 1999. Plasma and ovarian thyroxine levels in relation to sexual maturation and gestation in female Sebastes inermis. J. Fish Biol., 54, 370-379. 
Lam, T.J. 1983. Environmental influences on gonadal activity in fish. In: Fish Physiology, Vol. IXB, Hoar, W.S., D.J. Randall and E.M. Donaldson, eds., Academic Press. New York, pp. 65-116.

Lee, T.Y. and S.Y. Kim. 1992. Reproduction and embryonic development within the maternal body of ovoviviparous teleost, Sebastes inermis. Bull. Kor. Fish. Soc., 25, 413-431.

Lee, Y.D., S. Rho, Y.J. Chang, H.J. Baek and C.M. An. 1996. Sex differentiation of the rockfish, Sebastes schlegeli. J. Kor. Fish. Soc., 29, 44-50.

Manire, C.A., L.E.L. Rasmussen, D.L. Hess and R.E. Hueter. 1995. Serum steroid hormones and the reproductive cycle of the female'bonnethead shark, Sphyrna tiburo. Gen. Comp. Endocrinol., 97, 366-376.

Nagahama, Y., A. Takemura, K. Takano, S. Adachi and M. Kusakari. 1991. Serum steroid hormone levels in relation to the reproductive cycle of Sebastes taczanowkii and S. schlegeli, Env. Biol. Fish., 30, 31-38.

Park, M.E., S. Rho, S.C. Byun, C.H. Lee, H.J. Baek, Y.D. Lee and H.B. Kim. 2001. Regulation of copulation and parturition in black rockfish, Sebastes schlegeli by photoperiod and temperature. J. Kor. Aquacult. 14(3), 173-180.

Takahashi, H., K. Takano and A. Takemura. 1991. Reproductive cycles of Sebastes taczanowskii, compared with those of other rockfishes of the genus Sebastes. Env. Biol. Fish., 30, 23-29.

Takemura, A., K. Takano and H. Takahashi. 1987. Reproductive cycle of a viviparous fish, white-edged rockfish, Sebastes taczanowskii. Bull. Fac. Fish. Hokkaido Univ., 38(2), 111-125.

Wourms, J.P., B.D. Grove and J. Lombardi. 1988. The maternal-embryonic relationship in viviparous fishes. In: Fish Physiology, Vol. XIB, Hoar, W.S. and D.J. Randall. eds., Academic Press. New York, pp. 1-134.

Yamada, J. and M. Kusakari. 1991. Staging and the time course of embryonic development in kurosoi, Sebastes schlegeli. Env. Biol. Fish., 30, 103-110.

Zanuy, S., F. Prat, M. Carrillo and N. Bromage. 1995. Effects of constant photoperiod on spawning and plasma $17 \beta$-oestradiol levels of sea bass (Dicentrachus labrax). Aquat. Liv. Res., 8, 147-152.

(Received November 2003, Accepted February 2004) 